\title{
Análise dos impactos sociais e à saúde de grandes empreendimentos hidrelétricos: lições para uma gestão energética sustentável
}

\author{
Analysis of the social and health impacts of large hydroelectric \\ plants: lessons for a sustainable energy management
}

Adriana Renata Sathler de Queiroz ${ }^{1}$

Marcelo Motta-Veiga ${ }^{1}$

\footnotetext{
${ }^{1}$ Departamento de saneamento e saúde ambiental, Escola Nacional de Saúde Pública, Fundação Oswaldo Cruz. Rua Leopoldo Bulhões 1480/ 503, Manguinhos. 21041210 Rio de Janeiro RJ. sathler@ensp.fiocruz.br
}

\begin{abstract}
The main objective of this study was to analyze the social and health impacts resulting from the construction of the Tucurui (Pará, Brazil) and James Bay (Quebec, Canada) Hydroelectric Plants. The comparative method study used in analysis of the literature review revealed lessons to be learned from the national and international experience in order to ensure sustainable management of future major energy projects in Brazil. In this study, a successive negative domino effect was observed in terms of social impacts on jobs, income, sanitation, and culture, all with associated health problems. These included stress, nutritional and psychosocial disturbances, cardiopathies, as well as respiratory and digestive problems. The actions seeking to mitigate the effects of these negative impacts were slow to be implemented. Moreover, even though three decades have elapsed, these actions proved inefficient to resolve all the health and socio-environmental problems caused.
\end{abstract}

Key words Hydroelectric plants, Environmental management, Social impact, Environmental health
Resumo O objetivo deste estudo foi analisar os impactos à saúde e sociais resultantes da construção dos complexos de Usinas Hidrelétricas de Tucuruí (Pará, Brasil) e de James Bay (Quebec, Canadá). O método comparativo empregado na análise da revisão bibliográfica visou apontar lições, a partir da experiência nacional e internacional, para uma gestão sustentável de futuros grandes empreendimentos energéticos no Brasil. No estudo, foi observado um desencadeamento sucessivo de impactos sociais nas categorias de trabalho e renda, educação, saneamento, ambiente físico e cultura, associados aos agravos à saúde como estresse, distúrbios nutricionais, distúrbios psicossociais, cardiopatias, doenças respiratórias e digestivas. As ações mitigadoras e compensatórias foram tardiamente implementadas e visavam remediar os efeitos dos impactos negativos. Contudo, mesmo decorridos três décadas, essas ações se mostraram ineficientes para a resolução de todos os problemas ocasionados à saúde e socioambientais. Palavras-chave Hidrelétrica, Gestão ambiental, Impacto social, Saúde ambiental 


\section{Introdução}

Após um longo período de estagnação, o Governo Brasileiro tenta incentivar o crescimento econômico, esbarrando num futuro repleto de limitações infraestruturais. Historicamente, a oferta de energia é apontada como um dos gargalos a esse crescimento, onde a de origem hidrelétrica representa papel significativo. Atualmente, a geração hidráulica corresponde a $3 / 4$ da oferta total de energia elétrica no Brasil.

O Plano Decenal de Expansão de Energia (PDE 2020), recentemente divulgado pela Empresa de Projetos Energéticos (EPE), estima que nos próximos dez anos, a demanda total de energia deverá crescer em mais de 60\%. Com isso, a capacidade instalada nacional passará de $110.000 \mathrm{MW}$ em 2010 para 171.000 MW em 2020, devendo ser priorizadas as fontes de geração renováveis (hidráulica, eólica e biomassa).

Grandes empreendimentos hidrelétricos estão associados a significativos impactos ambientais, sociais e à saúde e têm sua viabilidade atrelada à obtenção das respectivas licenças ambientais. Nos próximos anos, dentro do Programa de Aceleração do Crescimento (PAC) estão previstas construções de dezenas de hidrelétricas, grande parte na região amazônica.

Alterações no modo de vida, associadas à inundação de áreas povoadas para formação do reservatório provocam o deslocamento compulsório e a ruptura social; a mudança no bioma com interferência na cadeia alimentar e a alteração nos processos de produção nativa de base agroextrativista e na caça.

Esses impactos sociais e seus efeitos à saúde não são considerados na fase do planejamento. Os Estudos de Impacto Ambiental (EIA) não incluem os impactos socioambientais, redundando em ações mitigadoras e compensatórias tardias e insatisfatórias. Nesse contexto, inviabilizase, desde a gestação, a possibilidade de uma gestão sustentável desses grandes empreendimentos hidrelétricos.

Reconhecendo-se essa lacuna na fase de planejamento, não ser possível prescindir de energia e a existência de uma tendência político-econômica de aproveitamento dos recursos hídricos para geração de energia, se faz relevante avaliar os determinantes sociais e os agravos à saúde de novos empreendimentos, a partir das lições “aprendidas" em experiências passadas.

O objetivo deste estudo foi analisar os impactos sociais e seus efeitos à saúde das populações atingidas pelas Usinas Hidrelétricas Tucuruí e Ja- mes Bay, visando apontar lições para a gestão sustentável de futuros projetos hidrelétricos no Brasil. Aprender com experiências passadas é um dos mais importantes instrumentos de prevenção, a fim de evitar que erros anteriores se repitam no futuro.

O processo de investigação se deu mediante uma revisão da literatura dos impactos sociais e à saúde pós-facto nas hidrelétricas de Tucuruí e de James Bay. Esse estudo enfatizou os impactos relacionados com a população indígena Parakanã, atingida diretamente pela construção da usina hidrelétrica (UHE) Tucuruí; e a população indígena Cree, atingida diretamente pela UHE James Bay. O levantamento desses impactos e das respectivas ações para o desenvolvimento regional consistiu em comparar a resiliência social e os processos de gestão dos impactos sociais.

\section{Impactos da UHE James Bay}

A Hidrelétrica James Bay, em Quebec, Canadá, consiste em oito barragens no estuário La Grande com capacidade total de 15.244 MW. No início do projeto, em 1971, a área era ocupada por aproximadamente 6.500 índios Cree, 5.000 índios Inuit e 450 índios Naskapi ${ }^{1}$.

As inundações para a construção dos reservatórios foram superiores a $11.000 \mathrm{~km}^{2}$ e atingiu os Cree que estavam a montante e impactando em menor escala os Inuit a jusante. James Bay se iniciou sem o Estudo de Impacto Ambiental (EIA) e sem levar em consideração os povos residentes na área afetada ${ }^{2}$.

Os Cree tiveram papel central em forçar uma gestão participativa. Ao tomar conhecimento do projeto, líderes Cree iniciaram uma série de manifestações políticas, aliando-se a grupos ambientalistas e à comunidade científica para se oporem à construção ${ }^{2-4}$.

Iniciou-se uma longa disputa jurídica, resultando na criação de acordos que visavam definir critérios para a ocupação e o uso das terras, com a inclusão no processo decisório das comunidades indígenas Cree, Inuit e Kativik. O acordo "The James Bay and Northern Quebec Agreement" (JBNQA) foi pioneiro e se tornou um marco nas questões de ocupação e uso das terras e da distribuição dos royalties ${ }^{2,5}$.

Através do JBNQA, os povos Cree e Inuit ganharam compensações financeiras e direitos sobre suas terras, negociaram um plano de autonomia regional à saúde, serviços sociais, educação e proteção ambiental ${ }^{6}$.

A avaliação do impacto social é parte do processo de avaliação ambiental canadense. O esco- 
po do EIA no JBNQA estabeleceu que os governos responsáveis e as agências criadas devessem levar em "consideração", uma série de princípios que incluíam a proteção da caça e da pesca, a mitigação dos impactos negativos ambientais e sociais sobre os povos indígenas e as comunidades nativas, bem como proteger o ecossistema ${ }^{9}$. No entanto, não garantiu uma avaliação adequada desses impactos visto que os estudos apresentam limitações no que tange às economias de subsistência ${ }^{2}$

O JBNQA representou a forma como os índios Cree "demonstraram claramente como um povo de caça pode proceder para definir o seu próprio futuro". Entretanto, o desenvolvimento industrial na região ameaçou o futuro da caça, e, os descumprimentos das obrigações estabelecidas no acordo pelo governo de Quebec, agravaram os conflitos demonstrando que o acordo não era suficiente para evitar os problemas socioambientais $^{5,7-10}$.

O JBNQA permitiu o controle institucional de políticas sociais pelos índios Cree que se organizaram socialmente para resolver os problemas coletivos e com isto consolidaram lideranças e desenvolveram sua capacidade de autonomia frente aos projetos desenvolvimentistas. Contudo, essa autonomia se apresentou como ambígua junto ao governo de Quebec. A efetiva inclusão dos nativos no sistema decisório gerou uma imagem positiva à província. Mas, não conseguiu cultivar uma relação baseada na cooperação entre o governo e as lideranças indígenas ${ }^{5,11}$.

Esse processo de adaptação às mudanças e de participação política se deu diante de subsequentes inundações, deslocamentos e dos consecutivos impactos cumulativos (abuso de álcool e droga, depressão, suicídio, violência, aculturação, etc.) que obrigava os nativos a repetidos e amplos ajustes no seu modo de vida na floresta.

Essa adaptação dos índios Cree às mudanças ambientais ocorreu durante a crise no mercado de pele de animais de 1960 até 1983, quando a exportação de pele animal foi proibida. O programa de renda garantiu direitos de caça territorial para consumo próprio, reforçando a produção de subsistência para aqueles que passavam longos períodos na floresta ${ }^{8}$, preservando uma matriz de valores e práticas culturais de épocas anteriores ${ }^{12,13}$.

Apesar da resiliência dos índios Cree às mudanças ambientais e do aporte político criado ao enfrentamento dos problemas socioambientais, as consequências dos impactos negativos em sua população foram imensos. Os principais impac- tos foram a desagregação social, associada à rápida desintegração do modo de vida tradicional; além dos aspectos de saúde, decorrente das mudanças sociais sem planejamento, externamente induzida pelo processo de urbanização, derivados do grande fluxo migratório e da relocação da comunidade ${ }^{13}$.

Atualmente, as preocupações com os efeitos cumulativos dos impactos centram-se na saúde dos jovens, principais vítimas das patologias sociais; e sobre suas incertezas quanto às escolhas laborais para a sua subsistência no futuro, uma vez que $3 / 4$ dos índios Cree não exercem mais atividades de subsistência ${ }^{6,9,14}$.

Os índios apresentam menor expectativa de vida e enfrentam riscos de obesidade e de doenças crônicas. A taxa de emprego é 10\% abaixo da população não-indígena, todavia, uma série de fatores combinados torna a população indígena mais vulnerável à pobreza ${ }^{15}$.

A contaminação ambiental repercutiu tanto na saúde quanto na economia Cree. O medo de intoxicação provocou mudanças na dieta, passando ao consumo de produtos industrializados, relacionando-se com os índices de diabetes e obesidade. Essa mudança de hábitos alimentares provocou impacto econômico e cultural, além de não fornecer uma conexão com a cultura e uma ligação com a terra ${ }^{16,17}$.

Os impactos sobre a renda são percebidos na ausência de equilíbrio saudável entre modo de vida tradicional e a economia dos assalariados. O principal fator de estresse provém do fato de que parte da população não tem acesso aos recursos necessários para se adaptar a essa nova dinâmica econômica. Os índios excluídos dos programas assistencialistas tornaram-se vulneráveis, principalmente os idosos ${ }^{11}$.

Segundo Torrie et al. ${ }^{11}$, a população Cree, de 1970 a 2003 teve redução na taxa de mortalidade, sendo os maiores problemas de saúde na década de 70 as altas taxas de problemas respiratórios e doenças infecciosas relacionadas às condições sanitárias precárias. Na década de 80 , houve melhorias nas condições sanitárias e a construção de novas unidades de saúde.

$\mathrm{Na}$ década de 90 a mortalidade infantil foi reduzida, embora ainda tenha permanecido acima da média de Quebec. Nos anos seguintes, as taxas de mortalidade da população Cree se aproximaram das de Quebec, porém as taxas de hospitalização continuaram acima da média. A mortalidade por doenças infecciosas diminuiu e as doenças respiratórias continuaram acima da média de Quebec. 
Os índios Cree são as principais vítimas de acidentes automobilísticos. A elevação nas taxas de acidentes fatais coincidiu com o uso de álcool e o aumento na aquisição de carros devido às condições de renda assalariada (43\% dos acidentes fatais estavam relacionados ao abuso de álcool).

A presença de diabetes surgiu nas últimas duas décadas, não sendo documentados casos da doença antes de 1975. A taxa de prevalência de diabetes em adultos passou de $1,9 \%$ para $13 \%$ no período de 1983 a 2003. Esses valores são quatro vezes a média nacional e provincial. Nos Cree, $43 \%$ dos casos estavam com menos de 40 anos. A obesidade corresponde a $60 \%$ da população Cree, o que está associado à mudança nos padrões de vida.

As taxas de hospitalização por doenças circulatórias e cardiovasculares da população Cree têm aumentado ao longo do tempo e são similares às taxas de Quebec. A prevalência de hipertensão arterial na população Cree é maior do que as taxas de Quebec. A taxa de mortalidade por câncer na região Cree permaneceu abaixo da média de Quebec. As doenças sexualmente transmitidas foram elevadas. Problemas psicossociais foram relatados, já na década de 80 , tais como violência familiar, depressão e suicídio, sendo atribuídos ao estresse associado à aculturação, ao desemprego e ao abuso de álcool. Esses dados revelam os efeitos a longo prazo dos impactos que acometem, principalmente, as novas gerações.

A incompatibilidade da carga horária de trabalho assalariado com as demandas de caça de subsistência associada ao baixo índice de contratação de trabalhadores indígenas cujas barreiras demonstram os entraves relacionados à formação, à educação, à experiência, a diferenças culturais e de estilo de vida. A instabilidade social e seus determinantes são os principais responsáveis pelo agravamento da saúde relacionados com fatores ambientais.

A legislação canadense institui que os estudos de impacto ambiental abranjam o conhecimento cientifico antecipado dos impactos sociais negativos na fase de planejamento do empreendimento. No entanto, na prática, o conhecimento das ciências sociais no processo de avaliação de impacto, muitas vezes tende a ser ignorado $\mathrm{d}^{6,13}$.

Grande parte da pesquisa de impacto social realizada para a Avaliação de Impacto Ambiental nunca foi considerada pelo proponente, HydroQuebec, tornando sua avaliação em grande parte inútil. Atualmente, as decisões políticas e operacionais no desenvolvimento de projetos hidrelétricos devem contemplar a avaliação de impacto socioambiental ${ }^{13}$.

\section{Impactos da UHE Tucuruí}

A UHE Tucuruí foi construída para atender a demanda de energia elétrica de diversos estados e de empreendimentos industriais. Tucuruí iniciou em 1975 tendo uma capacidade de geração de $8.370 \mathrm{MW}$ e um lago artificial de $2.917 \mathrm{~km}^{2}{ }^{18}$.

Tucuruí responde por $70 \%$ da energia elétrica produzida na Região Norte e 6\% do Brasil e sua área de influência abrange diversos municípios. As principais atividades econômicas desenvolvidas na região eram o extrativismo vegetal e a pecuária $^{19}$.

Os estudos de viabilidade técnica e econômica foram concluídos em 1974 pelo Consórcio Engevix-Ecotec. A avaliação socioeconômica caracterizou-se pelos aspectos que influenciariam na construção da usina, ou seja, as remoções dos ocupantes das áreas necessárias ao projeto para fins indenizatórios. Os impactos socioambientais tiveram um papel mínimo no processo decisório da construção de Tucuruí, que se baseou, principalmente, nos benefícios financeiros ${ }^{20}$.

O primeiro levantamento das alterações socioambientais só foi feito em 1977 e recomendava que a Eletronorte firmasse convênios com instituições de pesquisa para a realização de estudos ambientais. Mais tarde, alguns desses estudos foram transformados em Programas Ambientais ${ }^{18}$.

Em 1998, foram apresentados ao órgão licenciador propostas de programas de mitigação e compensação dos impactos. A renovação da licença de operação está condicionada à avaliação dos programas ambientais implementados. Os impactos de Tucuruí foram significativos tanto a montante quanto a jusante da barragem. A diferença dos impactos está no tratamento das ações mitigadoras e compensatórias.

A Lei n. ${ }^{\circ} 7.990 / 89$ instituiu a compensação financeira pela utilização dos recursos hídricos, com critérios de repartição baseado na proporção da área alagada ${ }^{20}$.

A área total inundada correspondeu a 3.513 $\mathrm{km}^{2}$ ou duas vezes o que foi projetado no estudo de viabilidade, uma área de inundação de 1.630 $\mathrm{km}^{2}{ }^{18,19}$.

A Eletronorte atribuiu esta imprecisão no dimensionamento das áreas inundadas à falta de tecnologia, sendo este um ponto de conflitos nos direitos compensatórios das áreas impactadas não alagadas, como é o caso da área de influência à jusante. Em 2010, esses percentuais foram homologados em sentença judicial (Tabela 1).

Em Tucuruí a economia das vilas a jusante da barragem foi destruída, criando, entre a popula- 
Tabela 1. Novos percentuais das áreas inundadas pelos reservatórios da UHE Tucuruí nos municípios do Estado do Pará

\begin{tabular}{lcc}
\hline Município & $\begin{array}{c}\text { Área } \\
\text { Inundada } \\
\left(\mathbf{k m}^{2}\right)\end{array}$ & $\begin{array}{c}\text { Área } \\
\text { Inundada } \\
(\%)\end{array}$ \\
\hline Breu Branco & 238,33 & 6,78 \\
Goionésia do Pará & 546,18 & 15,55 \\
Itupiranga & 154,90 & 4,41 \\
Jacundá & 342,48 & 9,75 \\
Marabá & 43,57 & 1,24 \\
Nova Ipixuna & 124,91 & 3,56 \\
Novo Repartimento & 1441,30 & 41,02 \\
Tucuruí & 621,62 & 17,69 \\
\hline
\end{tabular}

Fonte: ANEEL, $2010^{20}$.
O Pará registrou a maior elevação na taxa de desocupação passando de 5,36\%, em 2008, para 8,51\%, em 2009. Em 1991 a taxa de desocupação no município de Tucuruí era de 6,34\%, saltando para $16,93 \%$ em 2000 . A população urbana era de 46.014 em 1991, a rural 35.609. Em 2007, houve crescimento da urbana para 85.426, enquanto que a rural decresceu a partir de 1991, chegando em 2007 a $3.838^{22}$.

Entre 1991 e 2000, houve uma migração do campo à cidade, provavelmente pelos efeitos das transformações territoriais de ocupação e de uso ocorridas no entorno da UHE Tucuruí. Entre 1993 e 2007, a taxa incidência de tuberculose apresentou variação negativa de 4,8\%. O Pará possui 19 municípios prioritários à hanseníase, sendo que no período de 1990 a 2008, a taxa de detecção de hanseníase decresceu ${ }^{23}$.

Quanto às ilhas do lago de Tucuruí o quadro de saúde é delicado. A maioria dos municípios não possui saneamento. A água é retirada diretamente do lago para consumo humano ${ }^{24}$.

O abastecimento de água da maior parte da população provém de poços com armazenamento em caixas d'água, aumentando o risco da proliferação de dengue ${ }^{25}$.

O status quo dos Parakanã que ocupam a região atingida pela UHE de Tucuruí foi retratado no relatório de atividades do Programa Parakanã (PROPKN), apresentado a seguir.

A inundação para construção de UHE Tucuruí provocou a remoção de aldeias, relocadas no assentamento chamado de "loteamento Parakanã”. Essa construção, só não representou uma ameaça maior à sobrevivência dos Parakanã, porque eles já tinham certo grau de adaptação.

Tabela 2. incidência da pobreza dos municípios impactados pela UHE Tucuruí

\begin{tabular}{llc}
\hline Região UHE Tucuruí & \multicolumn{1}{c}{ Municípios } & Incidência de pobreza (\%) \\
\hline Montante & Breu Branco & 40,86 \\
& Goionesia do Pará & 46,16 \\
& Itupiranga & 45,43 \\
& Jacundá & 40,70 \\
& Marabá & 42,73 \\
& Nova Ipixuna & 41,61 \\
Novo Repartimento & 38,12 \\
Jusante & Tucuruí & 32,98 \\
& Baião & 55,71 \\
& Cametá & 52,36 \\
& Igaparé-Miri & 53,84 \\
& Mocajuba & 63,33 \\
\hline
\end{tabular}

Fonte: IBGE. Mapa da Pobreza e Desigualdade, $2003^{22}$. 
Apesar das alterações no processo de saúde-doença, houve crescimento populacional de $5 \%{ }^{26}$.

O mais importante grupo de doenças são as respiratórias agudas. Outro destaque foram as dermatológicas e as diarreicas que estão associadas ao banho no rio. Não houve caso confirmado de tuberculose e de hipertensão arterial. Problemas de ordem psicossocial, tais como depressão e distúrbios comportamentais têm sido registrados.

A presença de carros nas aldeias contribuiu para as taxas de acidentes. Doenças como Equinococose, Neotropical e Leischmaniose devido à convivência dos Parakanã com cachorros chamam a atenção.

A malária é um importante problema de saúde, onde o grupo de risco são crianças de até 10 anos. Em virtude do intenso deslocamento entre as aldeias antigas e novas, é possível evidenciar o impacto que o processo de mudança causou sobre o quadro epidemiológico da malária. Os anos que apresentaram alta incidência coincidiram com grande movimentação da população para formação de novas aldeias.

A educação é diferenciada e específica, onde a alfabetização na língua materna é uma obrigação legal. O currículo inclui cursos nas áreas de saúde, educação e produção ${ }^{23}$.

\section{Lições para uma gestão energética sustentável no Brasil}

Um problema recorrente nos projetos hidrelétricos é a negligência na predição dos impactos indiretos ainda na fase de planejamento ${ }^{27}$.

O custo social de empreendimentos hidrelétricos reflete-se nos indicadores sociais da região, os quais, no caso brasileiro, geralmente já apresentam elevados índices de pobreza expressos no status quo da educação, saúde, saneamento, habitação e trabalho das áreas afetadas ${ }^{21}$.

O processo de desapropriação e relocação causam impactos nas atividades de subsistência, sobretudo, para aqueles intimamente ligados à vida ribeirinha com base na agricultura, caça, pesca e extração vegetal. Este processo foi agravado pela dinâmica demográfica e social, observada pelo deslocamento migratório das populações atraídas pelo empreendimento ${ }^{18}$.

As experiências de Tucuruí e James foram marcadas por graves problemas relacionados com a população indígena envolvendo grandes disputas judiciais.

Os impactos, mais específicos que afetaram as populações indígenas foram: pressão antró- pica sobre as terras indígenas e intensificação dos conflitos entre indígenas, fazendeiros e assentados no entorno; educação inadequada à cultura indígena ocasionando a substituição da língua nativa pelo português; predomínio de doenças e problemas psicossociais características dos processos de aculturação como doenças sexualmente transmissíveis e de veiculação hídrica, violência, uso de álcool e drogas, tabagismo, desnutrição, entre outras ${ }^{28}$.

A eficácia das ações propostas foram polêmicas e consideradas inadequadas e insuficientes para reparação dos atingidos ${ }^{11}$. Estudos apontam casos de corrupção e a pouca efetividade das ações prometidas ${ }^{29,30}$.

$\mathrm{Na}$ experiência brasileira, a Eletronorte prevê investimentos em projetos de incentivo à agricultura, melhoria das condições pesqueiras, de saneamento básico e de comunicação social, além de investimentos em infraestrutura social, econômica e em ações de fortalecimento das atividades produtivas. Espera-se que essas "novas medidas" produzam níveis diferenciados de cidadania e de conscientização das populações ribeirinhas ${ }^{31}$.

Contudo, apesar desse otimismo da Eletronorte, cabe lembrar, que as lições do modelo gerencial adotado no Programa de Reassentamento em Tucuruí geraram desqualificação política e a descaracterização sociocultural, evidenciada pela imprevidência técnica e pela ausência de uma política negociada com interlocutores socialmente legitimados ${ }^{32}$.

Em Tucuruí a maioria dos impactos identificados (Quadro 1) está associada àqueles que ocorreram na área inundada, excluindo os municípios a jusante que sofreram impactos negativos e não receberam compensações financeiras em "royalties"18.

Recentemente, a Eletronorte reconheceu a importância dos impactos à jusante. Desta forma, a definição da área diretamente afetada não deveria se restringir ao percentual da área inundada, apesar da legislação em vigor manter esse critério para distribuição de royalties ${ }^{31}$.

Tanto em Tucuruí quanto em James Bay, problemas relacionados com a qualidade da água repercutiram na saúde e no modo de vida da população. Foram observadas altas taxas de doenças de veiculação hídrica, como diarreia e hepatite, a mortandade de peixes influenciou a piscicultura afetando a economia e subsistência da população. A contaminação por mercúrio, no caso de James Bay, foi determinante para a mudança dos hábitos alimentares e o aparecimento de distúrbios nutricionais. 
Quadro 1. Impactos Sociais da Usina Hidrelétrica Tucuruí

\begin{tabular}{|l|l|}
\hline \multicolumn{1}{|c|}{ Impacto } & \multicolumn{1}{c|}{ Efeitos } \\
\hline Formação do & Isolamento da população ribeirinha no enchimento do reservatório; \\
reservatório & Compensação financeira para os municípios que tiveram áreas inundadas através \\
Previsto área & da Lei dos Royalties, excluindo a jusante; \\
inundada de 1.630 & Migração interna, especialmente da população a jusante; \\
$\mathrm{km}^{2} ;$ sendo na $1^{\text {a fase }}$ & Ocupação irregular e desordenada; \\
$2.875 \mathrm{~km}^{2}$ e na $2^{\mathrm{a}}$ fase & Conflitos de uso;
\end{tabular}

Qualidade da água

Ausência de infraestrutura;

$2.800 \mathrm{~km}^{2}$, chegando

a $3.513 \mathrm{~km}^{2}$

Praga de mosquitos;

Riscos de manifestações de doenças de veiculação hídrica;

Alteração da qualidade da água;

Perda do sustento e renda;

Alagamento de vicinais no período de chuva;

Cadeia alimentar contaminada por metil-mercúrio;

Dificuldades de deslocamento e acesso a outras áreas e serviços.

\begin{tabular}{|c|c|}
\hline & $\begin{array}{l}\text { consequente abertura de poços; } \\
\text { Degradação da qualidade da água a jusante; } \\
\text { Riscos de manifestações de doenças de veiculação hídrica; }\end{array}$ \\
\hline Ictiofauna & $\begin{array}{l}\text { Perdas de zonas de pesca a jusante com redução do estoque pesqueiro; } \\
\text { Adaptação à pesca artesanal em detrimento dos meios de produção tradicional; }\end{array}$ \\
\hline $\begin{array}{l}\text { Deslocamento } \\
\text { compulsório } \\
\text { populacional } \\
\text { Inicial de } 4.407 \\
\text { pessoas chegando a } \\
10 \text { mil famílias }\end{array}$ & $\begin{array}{l}\text { Reassentamento em áreas impróprias (infertilidade dos solos e } \\
\text { comprometimento para a agricultura); } \\
\text { Instabilidade econômica; } \\
\text { Acampamentos improvisados ou em superlotados imóveis de núcleos urbanos em } \\
\text { implantação; } \\
\text { Alto índice de abandono e de comercialização de lotes; } \\
\text { Pressão na estrutura fundiária local; } \\
\text { Desestruturação da organização econômica e social;Conflitos de interesse e } \\
\text { mobilização comunitária; } \\
\text { Processo de emigração para outras áreas, principalmente para as ilhas. }\end{array}$ \\
\hline $\begin{array}{l}\text { Perfil } \\
\text { Epidemiológico }\end{array}$ & $\begin{array}{l}\text { Proliferação de mosquitos/aumento da incidência de malária; } \\
\text { Aumento no risco de metilação do mercúrio e sua introdução na cadeia } \\
\text { alimentar, com intoxicação dos povos ribeirinhos e indígenas da região; } \\
\text { Aumento dos riscos de manifestação de doenças de veiculação hídrica; } \\
\text { Aumento no risco de aparecimento de novas doenças, inclusive arboviroses; } \\
\text { Aumento da incidência de doenças a jusante; }\end{array}$ \\
\hline $\begin{array}{l}\text { Infraestrutura } \\
\text { Urbana }\end{array}$ & $\begin{array}{l}\text { Demanda superior a oferta de serviços sociais básicos; } \\
\text { Abandono dos lotes das áreas de reassentamento; }\end{array}$ \\
\hline Sociedades indígenas & $\begin{array}{l}\text { Remanejamento da Comunidade Parakanã; } \\
\text { Desestruturação das relações sociais das comunidades indígenas na região de } \\
\text { Tucuruí; } \\
\text { Aumento da incidência de doenças; } \\
\text { Pressões sobre as Terras Indígenas. }\end{array}$ \\
\hline Economia & $\begin{array}{l}\text { Geração de empregos; } \\
\text { Perda na produção pesqueira; } \\
\text { Mudança na estrutura produtiva agroextrativista; } \\
\text { Declínio da produção tradicional e estagnação econômica, sobretudo, a jusante } \\
\text { que teve queda da produtividade na extração do cacau nativo e do açaí das } \\
\text { margens do rio por causa das alterações na qualidade da água; } \\
\text { Urbanização desordenada; } \\
\text { Pesca comercial no reservatório; } \\
\text { Conflito entre pescador artesanal e comercial; } \\
\text { Queda de produção nas atividades tradicionais desenvolvidas nas várzeas } \\
\text { apontada pelos produtores locais; } \\
\text { Conflitos de interesse em decorrência da valorização da terra; } \\
\text { Expansão da exploração predatória da madeira; } \\
\text { Conflito fundiário }\end{array}$ \\
\hline
\end{tabular}


Desta forma, os novos projetos hidrelétricos deveriam abranger a análise dos efeitos à saúde humana provocados pela emissão de poluentes, visando obter parâmetros para a elaboração das ações e a tomada de decisões adequadas. Para ressaltar o descumprimento dessa lição básica, um novo empreendimento hidrelétrico em Belo Monte, também na região amazônica, já recebeu a Licença de Instalação sem ter realizado o inventário de fontes de poluição ${ }^{33}$.

Outra lição desconsiderada em Belo Monte, já bastante discutida em Tucuruí, é a imprecisão de números de famílias relocadas. Em Tucuruí, este erro resultou na relocação em áreas impróprias, inclusive para produção da agricultura, onde houve alto índice de abandono e de comercialização de lotes, e processos de emigração para outras áreas ${ }^{18}$.

No caso de Tucuruí ainda não houve solução para as iniquidades cometidas pelas irregularidades nos processos de expropriação e compensação, cujo passivo social ainda é sinônimo de luta e reivindicações empreitadas pelo Movimento dos Atingidos por Barragens (MAB).

Outra lição aprendida que continua sendo negligenciada é a necessidade da disponibilização antecipada de infraestrutura em saúde, educação e saneamento para reduzir os efeitos negativos do empreendimento. No caso da AHE de Belo Monte está previsto a realização dessas ações durante a implantação do projeto, o que representa um risco para a eficácia das ações mitigadoras.

\section{Discussão}

A construção de grandes barragens modifica o biótopo, antes coexistente em interdependência harmônica pessoa-ambiente, alterando os ecossistemas ribeirinhos. Isto pode ser representado pela noção de posicionamento e orientação espacial geográfica, essencial para a capacidade adaptativa da população autóctone, sobretudo, a indígena; que com o desaparecimento dos referenciais espaciais costumeiros para a sua orientação local, não raro, gera um sentimento de insegurança inicial que substitui o acúmulo de certezas práticas que a população possuía e que vinha sendo acumulado por séculos, passando de geração para geração.

Essa relação ambiental se dá naturalmente, através da complexidade do lócus que é observado em longo prazo: enchentes do curso de água; o regime pluviométrico; a variação sazonal; o comportamento faunístico e a previsibilidade da atividade migratória.
Desvio de rios, edificações e inundações impactam o ambiente com tal grandeza que todo o conhecimento acumulado durante toda uma existência se desvanece, requerendo da população atingida uma súbita adequação à realidade a qual se depara. A inicialização do processo de readaptação, difícil e penoso para os expropriados, e as facilidades aparentes que lhes podem ser ofertadas, destoam dos seus hábitos seculares. Ocorre, então, o estresse situacional, bem como o ocupacional, produzindo um trauma de desocupação, desvalorização de sua capacidade de operar com o meio.

A recuperação destes fatores psicossociais até o patamar de produtividade satisfatória requer: o resgate da capacidade exploratória do meio ambiente; a familiarização com todos os fatores constituintes e eventuais da ambiência em que, agora, estão reinseridos compulsoriamente; a valorização do conhecimento obtido através do instinto observacional-experimental usual em seu ecossistema familiar anterior; a conquista de uma relação segura com o meio ambiente novo, configurado antropicamente pelo povo dominante; a imposição inevitável para a aquisição de uma linguagem idiomática estrangeira, que lhe garanta a subsistência; o difícil entendimento do processo simbólico de uma economia monetária.

A fenomenologia do processo adaptativo para se tornar adequado e eficaz, atingindo um estágio de estilo de vida harmônico com o ambiente natural, depende da temporalidade do processo de ajuste pessoa - ambiente e de fatores externos intervenientes.

Tucuruí e James Bay possuem ambientes naturais com características distintas, porém com organizações socioculturais que advêm, essencialmente, da relação adaptativa com o meio físico e biótico nos quais estão inseridas. Verificou-se no processo de resiliência da população Cree, que comunidades indígenas que possuem lideranças e, culturalmente, estão mais organizadas para o enfrentamento de problemas no nível coletivo, têm melhores condições de implementar estratégias para lidar com as adversidades ambientais, impostas por pressões antrópicas, em busca de um equilíbrio ecossistêmico e da preservação do modo de vida.

Outro destaque de reflexão é a obliquidade dos mecanismos regulatórios e processuais para o EIA. Apesar de constar no escopo da avaliação ambiental os determinantes antrópicos, os estudos, por interesses diversos, são falhos no dimensionamento do capital humano e da capacidade da região em suportar as mudanças ambientais de repercussão social, uma vez que por conta das 
características ambientais, isoladas dos polos de desenvolvimento, apresentam recursos rudimentares para a subsistência. Desta forma, a qualidade das ações mitigadoras fica comprometida, reduzindo o seu potencial reparador do dano.

As lições de James Bay e Tucuruí evidenciam que os impactos ambientais provocam alterações sociais de alta repercussão na saúde individual e coletiva, seja na forma de agravos à saúde ou em consequências econômicas decorrente dos custos das doenças geradas pelos efeitos negativos do impacto.

Os agravos à saúde associados aos impactos socioambientais, frequentemente, são determinados por abruptas mudanças no modo de vida onde o indivíduo se depara com situações de frustração, medo e incapacidade para lidar com o problema, diminuindo a sua resiliência.

A lição em destaque neste estudo, é que o conhecimento das mudanças ecossistêmicas não é suficiente para uma ação mitigadora do estresse pós-traumático vivenciado pela população impactada (uns com mais intensidade do que outros). Embora, teoricamente, seja importante e necessário esse conhecimento para a compreensão ética e um olhar de sensibilidade psicossocial, inspirando ações práticas e satisfatórias para o povo autóctone afetado.

O estado de estresse pós-traumático constitui uma resposta retardada ou protraída a uma situação ou evento estressante, de curta ou longa duração, e de natureza excepcionalmente ameaçadora ou catastrófica. O sintoma de mudança de personalidade é o maior dano que o impacto psicossocial pode causar, podendo levar a uma situação de instinto compensatório que na maioria das vezes são insuficientes, e gerar ações iatrogênicas aprofundando a dependência, implicando na resiliência coletiva.

Assim, a discussão centrada no processo de transformação e aculturação, por vezes experimentado pela população indígena no decorrer das alterações ambientais causadas pela construção de grandes projetos hidrelétricos, requer um nível específico de análise de impacto social privilegiando os fatores psicossociais e antropológicos.

Os impactos sociais e à saúde provocados pelos projetos hidrelétricos James Bay e Tucuruí se assemelham; entretanto, os contrastes mais significativos observados no estudo dessas duas experiências se refere aos efeitos positivos da gestão coparticipativa da população indígena de Quebec no processo decisório, o que não ocorreu no caso de Tucuruí.

Com relação ao desenvolvimento regional, o Pará tem os piores índices de pobreza revelando a ineficiência das compensações financeiras em gerar investimentos capazes de produzir riqueza e bem-estar da população. As regras atuais que disciplinam a cobrança de royalties criam nichos de riqueza aparente, e evidenciam a incoerência entre os critérios de distribuição para as áreas de influência do projeto.

$\mathrm{O}$ efeito contextual da riqueza municipal na saúde ocorre porque municípios mais pobres fornecem piores serviços de saúde, então a qualidade dos serviços é uma variável intermediária entre o efeito da pobreza municipal e a saúde da população ${ }^{27}$.

Embora exista um Projeto de Lei para a inclusão dos municípios situados a jusante, a Lei 9.648/ 90 determina que os critérios de compensação financeira se dê pelo percentual de área inundada.

Outras consequências, provenientes das informações ambíguas geradas foram: o isolamento da população ribeirinha; a dupla realocação, com inundação das áreas nas quais foram reassentados os expropriados; migração interna, especialmente da população a jusante acarretando em ocupação irregular e desordenada, bem como a ausência de infraestrutura, infestação de mosquitos e riscos de manifestações de doenças de veiculação hídrica como a diarreia e dermatites, desaparecimento dos peixes, a má qualidade da água, bem como a queda na produtividade agrícola das áreas de várzea, além de mudanças microclimáticas $^{19,34}$.

Os impactos sociais são bastante evidentes nas populações indígenas Parakanã e Cree. Na experiência brasileira (Quadro 1), sem recursos legais e políticos para se posicionar frente às ações de desenvolvimento criou-se um total estado de dependência, além de uma brusca redução populacional no período de construção da Transamazônica e da UHE Tucuruí ${ }^{29,31,35}$.

Esse quadro só veio a mudar após a implantação do PROKN, cujo objetivo principal foi o retorno à autossustentação da comunidade através de ações nas áreas de saúde, educação, produção agrícola e vigilância dos limites territoriais. No entanto, o status quo dos Parakanã revela que este processo é lento, implicando em apoios financeiros até que se atinja o objetivo de sustentabilidade. Os diversos impactos sociais não mensurados foram ignorados pelo órgão licenciador, culminando nos impactos à saúde analisados.

As experiências de James Bay e Tucuruí descritas neste estudo retratam os complexos impactos sucessíveis de difícil controle pós facto, principalmente, em ambientes isolados e com infraestrutura precária, ressaltando a importância de ações preventivas. Contudo, após dezenas de anos 
das experiências negativas de James Bay e de Tucurí, parece que essas lições ainda não foram aprendidas. Os novos empreendimentos hidrelétricos na região amazônica demonstram que o processo decisório ainda é norteado, prioritariamente, por interesses políticos e econômicos, dando pouca ênfase aos aspectos sociais e ambientais $^{29,31,35}$.

\section{Conclusão}

As experiências descritas neste estudo mostram o desencadeamento sucessivo de impactos, irrefutáveis por negligência na fase do planejamento do projeto. As ações mitigadoras e compensatórias implementadas, a fim de remediar os efeitos dos impactos negativos, mostraram-se, ao longo de décadas, insuficientes para a solução dos problemas socioambientais.

O status quo das populações estudadas retratam a incapacidade de se controlar os impactos cumulativos e sinergéticos causados pelas hidrelétricas. A defasagem dos índices esperado e real, infere que a vontade política não se debruça no detalhamento de todas as implicações socioambientais envolvendo o planejamento do projeto hidrelétrico.

Os programas de cunho assistencialista, financiados por estatais consorciadas com empreiteiras, se mostram necessários no resgate da autono- mia e remediação dos impactos. O maior problema é a garantia de continuidade dos programas.

Contudo, o entendimento da relevância do impacto social para as vertentes de um planejamento energético sustentável é o aspecto que mais evoluiu, todavia, a Avaliação Ambiental Integrada não tem sido feita na sequência e nos moldes em que foi concebida, ou seja, o licenciamento de viabilidade do projeto hidrelétrico é concedido antes da devida conclusão dos estudos de impacto socioambiental.

Logo, a gestão participativa e a conduta ética e imparcial de todos os atores envolvidos no processo de avaliação e viabilidade do projeto, é um determinante para a qualidade da Avaliação de Impacto Ambiental e Social e respectiva eficácia das ações mitigadoras propostas.

Desenvolver metodologias de gestão participativa para avaliação dos impactos sociais, que permita mais transparência nos programas e no monitoramento do desempenho dos indicadores de forma a identificar a eficiência das ações realizadas, contribuindo assim com a Avaliação Ambiental Estratégica, pode ser uma alternativa para a efetiva mitigação dos impactos sociais e à saúde, atrelados ao desenvolvimento regional.

As experiências dos impactos negativos produzidos pela construção das hidrelétricas de Tucuruí e de James Bay analisadas neste estudo devem ser internalizadas, aprendidas e servir como lições para uma gestão sustentável de futuros grandes empreendimentos energéticos no Brasil. 


\section{Colaboradores}

ARS Queiroz foi responsável pela condução teórica e metodológica da pesquisa e trabalhou na elaboração e redação do texto; M Motta-Veiga atuou na orientação e na estruturação teórica e metodológica da pesquisa, bem como na redação final do texto.

\section{Referências}

1. Denis R. Lessons Derived from the Environmental Follow-up Programs on the La Grande Rivière, Downstream from the La Grande-2AQ Generating Station, James Bay, Quebec, Canada. In: International Association for Impact Assessment annual meeting. Hong Kong; 2000.

2. Peters EJ. Native People and the Environmental Regime in the James Bay and Northern Quebec Agreement. Journal Arctic 1999; 52(4):395-410.

3. Warner S, Coppinger R. Hydroelectric power development at James Bay: establishing a frame of reference. In: Horning JF, organizador. Social and environmental impacts of the James Bay hydroelectric project. Montréal, Ithaca: McGill-Queen's Press; 1999. p. 19-40.

4. Peloquim C, Berkes F. Local knowledge, subsistence harvests, and social-ecological complexity in James Bay. Human Ecology 2009; 37(5):533-545.

5. Lamontagne A. Defending the Land: sovereignty and forest life in James Bay Cree society. Rev Estudos e Pesquisas sobre as Américas 2009; 3(1):1-7.

6. Senécal P; Égré D. Human Impacts of the La Grande Hydroelectric Complex on Cree Communities in Quebec. Impact Assessment \&Project Appraisal 1999; 17(4):319-329.

7. Canadá. Gouvernement du Quebec. James Bay and Northern Quebec Agreement and Complementary Agreements (JBNQA). Quebec: Publication prepared by the Secretariat aux affaires autochthones. Quebec: Department of Indian and Northern Affairs; 1997.

8. Feit HA. Waswanipi Cree management of land and wildlife: Cree cultural ecology revisited. In: Cox B, editor. Native People, Native Lands: Canadian Indians, Inuit and Métis. Ottawa: Carleton University Press; 1987.

9. Warner S. The Cree people of James Bay: assessing the social impacts hydroelectric dams and reservoirs. In: Horning JF, organizador. Social and environmental impacts of the James Bay hydroelectric project. Montréal, Ithaca: McGill-Queen's; 1999. p. 93-120.

10. Canadá. Gouvernement du Quebec. Northeastern Quebec Agreement - NEQA. 1990. Canada: Department of Indian and Northern Affairs; 2012.

11. Torrie J, Bobet E, Kishchuk N, Webster A. The evolution of health status and health determinants in the Cree region (Eeyou Istchee): Eastmain-1-A powerhouse and Rupert diversion sectoral report - Context and Findings. V. 2. Montreal: Cree Board of Health and Social Services of James Bay; 2005. (Série 4, n. 3)

12. Berry JW. Immigration, Acculturation, and Adaptation. Canadá: Applied Psychology: An International Review, 1997; 46(1):5-68.

13. Tanner A. Culture, Social Change, and Cree Opposition to the James Bay Hydroelectric Development. In: Horning JF, org. Social and environmental impacts of the James Bay hydroelectric project. Montréal, Ithaca: McGill-Queen's Press; 1999. p. 121-140.

14. Whiteman G. The Impact of Economic Development in James Bay, Canada: The Cree Tallymen Speak Out. Organization \& Environment 2004; 17(4):425-448. 
15. Noël A, Larocque F. Aboriginal Peoples and Poverty in Canada: Can Provincial Governments Make a Difference? Montréal: Paper prepared for the Annual Meeting of the International Sociological Association's Research Committee 19 (RC19); 2009.

16. Brassard P, Robinson E, Lavallee C. Prevalence of diabetes mellitus among the James Bay Cree of northern Quebec. Can Med Assoc 1993; 149(3):303-307.

17. Roebuck BD. Elevated Mercury in Fish as a Result of the James Bay Hydroelectric Development: Perception and Reality. In: Horning In: Horning JF, organizador. Social and environmental impacts of the James Bay hydroelectric project. Montréal, Ithaca: McGill-Queen's Press; 1999. p. 73-92.

18. Centrais Elétricas do Norte do Brasil. Manual do sistema de gestão ambiental - UHE Tucuruí. Brasília: Eletronorte; 2010.

19. La Rovere EL, Mendes FE, organizadores. Tucuruí Hydropower Complex, Brazil. WCD; 2000.

20. Agência Nacional de Energia Elétrica (Aneel). A compensação financeira e o seu município. Brasília: Aneel; 2007.

21. Fearnside P. Environmental impacts of Brazil's Tucuruí dam: unlearned lessons for hydroelectric development in Amazonia. Env Manag 2001; 27(3): 377-396.

22. Governo do Estado do Pará; Instituto de Desenvolvimento Econômico, Social e Ambiental do Pará; Secretaria de Estado de Planejamento, Orçamento e Finanças. Relatório do Mapa da Exclusão Social. Belém: IDESP/SEPOF Pará; 2010.

23. Brasil. Ministério da Saúde. Sistema de Vigilância em Saúde: Relatório de Situação - Pará. Brasília: MS; 2009.

24. Araujo ORA. Os Territórios protegidos e a Eletronorte na área de influência da UHE Tucuruí/PA [dissertação]. Belém: Universidade Federal do Pará; 2008.

25. Calijuri ML, Santiago FA, Camargo AR, Moreira Neto FR. Estudo de indicadores de saúde ambiental e de saneamento em cidade do Norte do Brasil. Eng Sanit Ambient 2009; 14(1):19-28.
26. Carvalho JPF, organizador. Programa Parakanã PROPKN - Relatório de Atividades. Belém: Eletronorte/ Funai; 2009

27. Celeste RK; Nadanovsky P. Aspectos relacionados aos efeitos da desigualdade de renda na saúde: mecanismos contextuais. Cien Saude Colet 2010; 15(5): 2507-2519.

28. Manyari VW, Carvalho Jr AO. Environmental considerations in energy planning for the Amazon region: Downstream effects of dams. Energy Policy 2007; 35(12):6526-6534.

29. Sudo YC. Plano popular de desenvolvimento sustentável à jusante da UHE Tucuruí. Brasília: Eletronorte; 2008.

30. Conselho de Defesa dos Direitos da Pessoa Humana (CDDPH). Atingidos por barragens. Brasília: CDDPH; 2007.

31. Rolnik R, Schasberg B, Pinheiro MO, organizadores. Plano diretor participativo. Brasília: Ministério das Cidades, Secretaria Nacional de Programas Urbanos; 2005.

32. Mougeot JL. Planejamento Hidroelétrico e Reinstalação de Populações na Amazônia: Primeiras Lições de Tucuruí. In: Aubertin C, organizador. Fronteiras. Brasília: UnB/ORSTOM; 1998.

33. Acselrad H. Mercado de terras e meio ambiente em áreas de grandes projetos de investimento - o caso da Usina Hidrelétrica de Tucuruí. Estud. Soc. e Agric. 2010; 18(1):158-192.

34. Beaty S. O movimento dos atingidos pela barragem de Tucuruí: uma história oral. Providence: Brown University; 2008.

35. Centrais Elétricas do Norte do Brasil. Relatório de responsabilidade socioambiental. Brasília: Eletronorte; 2007. 